\title{
New Bone Formation in Tuberculous-Infected Vertebral Body Defect after Administration of Bone Marrow Stromal Cells in Rabbit Model
}

\author{
Ahmad Jabir Rahyussalim ${ }^{1}$, Tri Kurniawati ${ }^{2}$, Nurjati Chairani Siregar ${ }^{3}$, \\ Agus Syahrurachman ${ }^{4}$, Ismail Hadisubroto Dilogo ${ }^{1}$, Diah Iskandriati ${ }^{5}$, Arni Diana Fitri ${ }^{6}$ \\ ${ }^{1}$ Department of Orthopaedic and Traumatology, Faculty of Medicine, University of Indonesia, Jakarta, Indonesia \\ ${ }^{2}$ Stem Cell and Tissue Engineering Cluster, MERC Faculty of Medicine University of Indonesia, Jakarta, Indonesia \\ ${ }^{3}$ Department Patologi Anatomic, Faculty of Medicine, University of Indonesia, Jakarta, Indonesia \\ ${ }^{4}$ Department Microbiologi Clinic, Faculty of Medicine, University of Indonesia, Jakarta, Indonesia \\ ${ }^{5}$ Primata Research Center, Bogor Agricultural Institute, Bogor, Indonesia \\ ${ }^{6}$ Veterinary Teaching Hospital, Bogor Agricultural Institute, Bogor, Indonesia
}

Study Design: Preliminary experimental study using a rabbit spondylitis model.

Purpose: To observe the ossification in a micro-environment containing live Mycobacterium tuberculosis transplanted with bone marrow stromal cells (BMSCs) in rabbits.

Overview of Literature: BMSCs differentiate to osteoblasts and then osteocytes during ossification. Mycobacterium tuberculosis does not affect BMSC growth in vitro.

Methods: Six rabbits were divided into two groups of three rabbits. One group was positive for spondylitis tuberculosis by culture, polymerase chain reaction (PCR), and histopathologically. The other group was positive by PCR and histopathologically. Both groups were treated using BMSC transplantation and anti-tuberculosis drugs. After 6 weeks, ossification was evaluated by enumerating the number of osteoblasts, osteocytes, and lesion level of calcium.

Results: Mean number of osteoblasts was $207.00 \pm 31.00$ in the first group and $220.33 \pm 73.46$ in the second group. Mean number of intra-lesions osteocytes was in the first and second group was $18.33 \pm 30.04$ and $31.00 \pm 26.87$, respectively. Mean calcium level in the first group and second group was $2.94 \% \pm 0.89 \%$ and $2.51 \% \pm 0.13 \%$, respectively. Total ossification score in the first and second group was 31.00 and 25.67 , respectively.

Conclusions: Mycobacterium tuberculosis provides support for new bone formation by stimulating intra-lesion calcium metabolism. The microscopic environment containing live Mycobacterium tuberculosis enhances ossification.

Keywords: Calcium level; Mycobacterium tuberculosis; Ossification

\section{Introduction}

Spondylitis tuberculosis is an infectious disease of the spine caused by Mycobacterium tuberculosis (M. tuberculosis). Spondylitis tuberculosis causes a defect of the corpus that can lead to spinal instability and disturbance of surround-

\footnotetext{
Received Jun 1, 2015; Revised Jun 20, 2015; Accepted Jun 21, 2015

Corresponding author: Ahmad Jabir Rahyussalim

Department of Orthopaedic and Traumatolgy, Faculty of Medicine, Universitas Indonesia,

Jalan Salemba 6, Kelurahan Kenari, Kecamatan Senen, Jakarta Pusat, DKI Jakarta, 10320, Indonesia

Tel: +62-21-315-5996, Fax: +62-21-392-9655, E-mail: rahyussalim71@ui.ac.id
} 
ing tissue. Healing of the bacterial infection is determined by the severity of corpus defect and the degree of bacterial infection in the spine [1]. The mainstay therapy of is surgery. However, results can be unsatisfactory with no spinal fusion evident. As an alternative treatment, we explored the documented potential of bone marrow stromal cells (BMSCs) in restoring the structural abnormalities in spondylitis tuberculosis cases [2-8].

Ossification is a part of bone formation that is influenced by cellular differentiation, osteocyte activity, and calcium deposit [6]. M. tuberculosis does not influence the differentiation of BMSCs into osteoblasts and ultimately to osteocytes in vitro, and decrease calcium deposition within the defect $[7,8]$. In the present study, we evaluated ossification in spondylitis tuberculosis affected bone by quantifying osteoblasts, osteocytes, and the calcium level of infected bone. The purpose of this research is to evaluate the interaction between $M$. tuberculosis and bone ossification in vivo using a rabbit model of spondylitis tuberculosis [6,7].

\section{Materials and Methods}

\section{Approval}

This research was an interventional research using an animal model. The research protocol was been reviewed and approved by the Animal Care and Use Committee (ACUC) PT Bimana Indomedical (No. R.02-12-IR), Komisi Pengawasan dan Kesejahteraan Penggunaan Hewan Percobaan IPB Animal Hospital (No. 02-21012), and the Research Ethical Committee of the Medical Research Unit (FMUIRSCM No. 521/PT02.FK/ETIK/2012). The majority of the research was conducted at these locales.

\section{Rabbit model}

Rabbits were inoculated directly with $M$. tuberculosis within the vertebral body (corpus) as described elsewhere [9-13]. Of the 14 rabbits inoculated, the intervention group and control group each comprised three rabbits. All steps were done on general anaesthesia using ketamin 44 $\mathrm{mg} / \mathrm{kg}$. Each rabbit was positioned facing laterally with the left back facing the operator. Identification of the 12th thoracic vertebrae was done by palpating the 12 th rib then tracing it to the transverse process. An incision was made transversally to the T12 vertebrae starting from the spinous process $3-5 \mathrm{~cm}$ towards the left lateral penetrating skin and subcutaneous tissue. Paraspinal muscles were dissected until the 12th rib, transverse process, and 12th thoracal lamina. The bone was identified to determine the 12th thoracic body before a hole was drilled in the mid-point of the body $\pm 5 \mathrm{~mm}$ from transverse process for 6 to $10 \mathrm{~mm}$ using a $1.5-\mathrm{mm}$ drill bit. In the intervention group, up to $0.2 \mathrm{~mL}$ of a $M$. tuberculosis suspension containing $1 \times 10^{8}$ viable bacteria per $\mathrm{mL}$ was inoculated aseptically into the hole made in the corpus. After a $5 \mathrm{~min}$ exposure to the open air the hole was closed by suturing the fascia, muscles, and subcutaneous tissue. In the control group, rabbits were inoculated with $0.2 \mathrm{~mL}$ of a $\mathrm{NaCl}$ solution. Surgical wounds were closed layer-by-layer and the skin was sutured one-by-one using 3.0 vycril and then closed by bandage. Rabbits were returned to their cage and observed until they recovered from anaesthesia. Isotonic $\mathrm{NaCl}$ was infused subcutaneously and $3 \mathrm{mg} / \mathrm{kg}$ ketoprofen was given for first 3 days post-inoculation. Rabbits were then held individually in cages for 8 weeks. Examinations during that time included acid fast bacilli staining, culture, polymerase chain reaction (PCR), and histopathology. The intervention group of rabbits were positive for culture, PCR, and histopathology. The control group of rabbits were positive for PCR and histopathology. Both groups received debridement, anti-tuberculosis regimen [1], scaffold placement of hydroxyapatite, and BMSC transplantation into the defective corpus. BMSC transplantation was done in conjunction with the debridement, defect creation, and implant fixation procedure. Defects were filled with $150 \mathrm{mg}$ hydroxyapatite scaffold and transplanted with $6 \times 10^{6}$ BMSCs. During the incubation period, each rabbit was examined clinically. After 6 weeks of follow-up, each rabbot was euthanized and the degree of ossification was assessed. The parameters measured objectively were osteoblast count, osteocyte count, and calcium level. Osteoblasts and osteocytes were microscopically enumerated in hematoxylin and eosin (H\&E) stained specimens by two evaluators. The results from each rabbit in a group were combined to determine the mean value. Calcium level was determined using atomic emission spectroscopy.

\section{Results}

Microscopy evaluation of H\&E stained specimens at 400 times magnification (Fig. 1) determined the mean \pm 

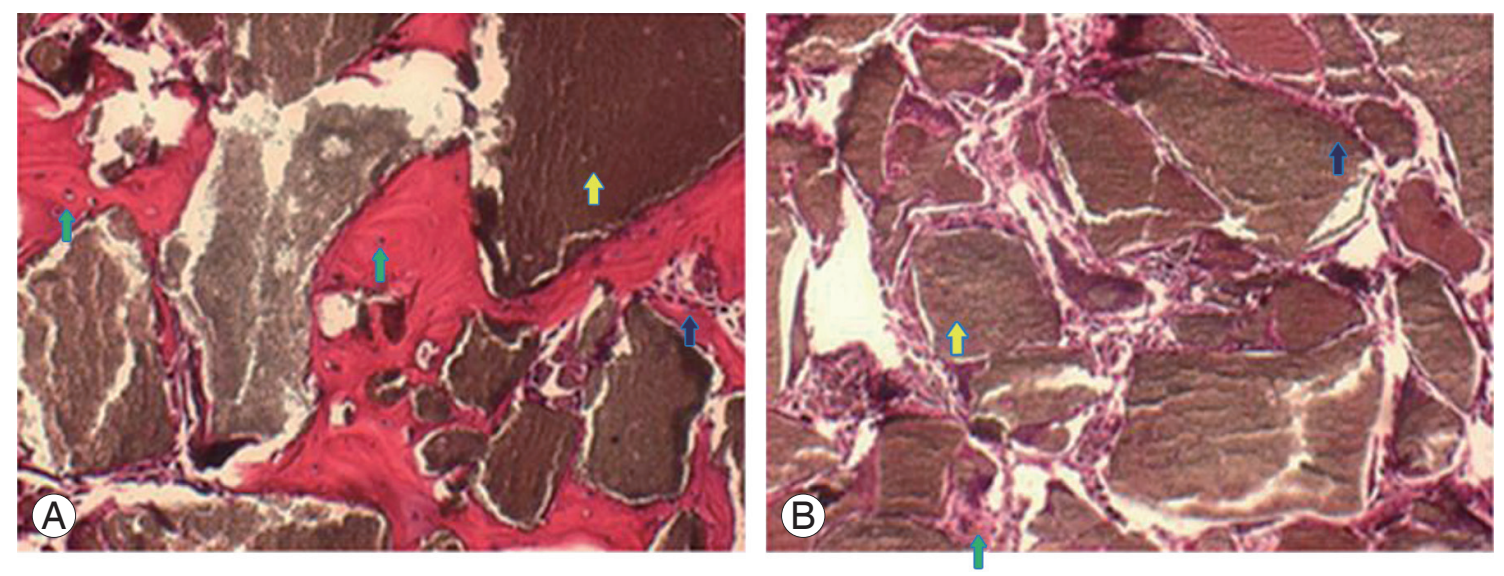

Fig. 1. Evaluation of hemotoxylin and eosin-stained sagital section of defect tissue by microscopy at 400 times magnification. (A) Application of BMSCs in rabbit with spondylitis tuberculosis reveals inflammatory cells around the scaffold (green arrows). Osteoblast rimming (dark blue arrow) can be seen around the bony island (yellow arrow) as well as several osteocytes indicating good ossification (dark blue arrow). (B) A preparation from a rabbit that did not receive BMSCs. Few osteoblasts are evident (green arrow), with no osteocytes present. BMSCs, bone marrow stromal cells.

Table 1. Osteoblast, osteocyte count and calcium level of bone defect in both groups

\begin{tabular}{|c|c|c|c|c|c|}
\hline \multirow{2}{*}{ Variables } & \multicolumn{2}{|c|}{ Intervention } & \multicolumn{2}{|c|}{ Control } & \multirow{2}{*}{$p$-value } \\
\hline & $n=3$ & Mean $\pm S D$ & $n=3$ & Mean $\pm S D$ & \\
\hline Osteoblast & 3 & $220.33 \pm 73.46$ & 3 & $207.00 \pm 31.00$ & NA \\
\hline Osteocyte & 3 & $18.33 \pm 30.04$ & 3 & $31.00 \pm 26.87$ & NA \\
\hline Calcium Level & 3 & $2.94 \pm 0.89$ & 3 & $2.51 \pm 0.13$ & NA \\
\hline
\end{tabular}

SD, standard deviation; NA, not applicable.

Table 2. Ossification score of each subject

\begin{tabular}{|c|c|c|c|c|c|c|}
\hline Subject coding & Group & $\begin{array}{l}\text { Osteoblast count } \\
\text { (score) }\end{array}$ & $\begin{array}{l}\text { Osteocyte count } \\
\text { (score) }\end{array}$ & $\begin{array}{l}\text { Calcium level } \\
\text { (score) }\end{array}$ & Total score & $\begin{array}{l}\text { Ossification } \\
\text { grade }\end{array}$ \\
\hline K3164 & Control & 5 & 15 & 15 & 35 & Good \\
\hline K0505 & Control & 5 & 5 & 15 & 25 & Normal \\
\hline K2964 & Control & 1 & 1 & 15 & 17 & Delayed \\
\hline K0509 & Intervention & 15 & 1 & 15 & 31 & Good \\
\hline K3264 & Intervention & 1 & 15 & 15 & 31 & Good \\
\hline K0519 & Intervention & 15 & 1 & 15 & 31 & Good \\
\hline
\end{tabular}

Total score, 18 (delayed); $18-30$ (normal); >30 (good).

standard deviation osteoblast count as $207.00 \pm 31.00$ in the intervention group and $220.33 \pm 73.46$ cells in the control group. The respective osteocyte count was $18.33 \pm 30.04$ and $31 \pm 26.87$. The respective mean calcium level was $2.94 \% \pm 0.98 \%$ and $2.51 \% \pm 0.13 \%$. All rabbits in the intervention group displayed good ossification based on the Ossification score (Table 1). Results in the control group were varied, with delayed, normal, and good ossification evident in one rabbit each (Table 2).

\section{Discussion}

This study used a rabbit spondylitis tuberculosis model created by injection of $20 \times 10^{6} \mathrm{cfu} / \mathrm{mL}$ M. tuberculosis, which was sufficient to cause infection. Rabbits with demonstrated infection were included in this study. All rabbits were treated with appropriate antibiotics in an effort to quell the infections. The six rabbits with persisting infections were used for the study. The oral anti-tuberculous 
drugs that were given aimed to prevent systemic infection, which could be fatal, and to reduce the number of viable M. tuberculosis colonies in the lesion and systemic circulation. The treatment was synchronized with the use of oral anti-tuberculous drugs given 2 weeks before surgery, except in emergency cases.

We evaluated specimens obtained at the time of surgery and euthanasia. The cultured specimens obtained after surgery were used to distinguish the two groups of rabbits. The euthanized specimens were used for purposes unrelated to the present study.

Diagnosis was determined by histopathologic examination, reflecting the specificity, accuracy, and rapid performance time of the approach. Acid fast bacilli test, culture, and PCR were also performed to determine the choice of treatment. Debridement of the infected lesion was done while creating an artificial defect to measure the volume defect. To achieve solid intervertebral fusion, $1.6 \times 10^{6}$ BMSCs and hydroxyapatite scaffold was transplanted. BMSCs were provided because the large and inflamed defect could disturb new bone formation, considering the anti-inflammatory activity of the cells. The rational was the use of BMSCs to dampen inflammation and other immune responses to help kill $M$. tuberculosis.

During new bone formation, ossification continued in rabbits with ongoing $M$. tuberculosis infection and in the absence of infection, and even without debris after debridement. Administration of BMSCs at the site of bone defect in the presence of $M$. tuberculosis infection resulted in cell differentiation and subsequent ossification. The numbers of osteoblasts and osteocytes were similar to the numbers evident in rabbits without infection. But, infection was associated with disrupted bone matrix formation, as evident by the reduced osteocyte to osteoblast ratio compared to the ratio in uninfected rabbits and greater calcium deposition in infected rabbits.

The observations support the view M. tuberculosis infection increases the mobilization of calcium towards lesion for ossification. In this environment, the rate of bone cell metabolism could also increase, resulting in more bone mass formation. Fewer osteocytes are trapped in this environment, hence the bone mass that forms is relatively osteocyte-poor contains.

The ossification score was used to evaluate the ossification process in the manufactured defects. This score is a novel approach based on the osteoblast count, osteocyte count and bone calcium level. Each of the three parameters
Table 3. Ossification scoring determination

\begin{tabular}{lccc} 
Measurable & \multicolumn{3}{c}{ Result score } \\
\cline { 2 - 4 } factor & Negative & Normal & Positive \\
\hline Osteoblast count & & 5 & 15 \\
Lesion T12 & 1 & 5 & 15 \\
\hline Osteocyte count & & & \\
Lesion T12 & 1 & 5 & 15 \\
\hline Calcium level & & & 45 \\
\hline Lesion T12 & 1 & & \\
\hline Total & & & \\
\hline
\end{tabular}

Table 4. Simulasion of ossification score

\begin{tabular}{|c|c|c|c|}
\hline $\begin{array}{l}\text { Osteoblast } \\
\text { count }\end{array}$ & $\begin{array}{c}\text { Osteocyte } \\
\text { count }\end{array}$ & Calcium level & Total score \\
\hline 1 & 1 & 1 & 3 \\
\hline 1 & 1 & 5 & 7 \\
\hline 5 & 1 & 1 & 7 \\
\hline 1 & 5 & 1 & 7 \\
\hline 1 & 5 & 5 & 11 \\
\hline 5 & 1 & 5 & 11 \\
\hline 5 & 5 & 1 & 11 \\
\hline 5 & 5 & 5 & 15 \\
\hline 15 & 1 & 1 & 17 \\
\hline 1 & 1 & 15 & 17 \\
\hline 1 & 15 & 1 & 17 \\
\hline 15 & 1 & 5 & 21 \\
\hline 1 & 5 & 15 & 21 \\
\hline 1 & 15 & 5 & 21 \\
\hline 5 & 1 & 15 & 21 \\
\hline 15 & 5 & 1 & 21 \\
\hline 5 & 15 & 1 & 21 \\
\hline 5 & 15 & 5 & 25 \\
\hline 15 & 5 & 5 & 25 \\
\hline 5 & 5 & 15 & 25 \\
\hline 15 & 15 & 1 & 31 \\
\hline 1 & 15 & 15 & 31 \\
\hline 15 & 1 & 15 & 31 \\
\hline 15 & 5 & 15 & 35 \\
\hline 5 & 15 & 15 & 35 \\
\hline 15 & 15 & 5 & 35 \\
\hline 15 & 15 & 15 & 45 \\
\hline
\end{tabular}

Total score, 18 (delayed); 18-30 (normal); > 30 (good). 
were rated as as negative (scored as 1), normal (scored as 5 ), or positive (scored as 15), and added together to determine the overall score (Table 3). A score $<18,18-30$, and $>30$ indicated delayed ossification, normal ossification, and good ossification, respectively.

The three rabbits in the intervention group displayed an ossification score exceeding 30 . In other words, ossification in infected rabbits was good (Table 4). Of In the three uninfected rabbits, two scored $<31$ with the remaining rabbit scoring $<17$, indicative of delayed bone formation. The results suggest that spondylitis tuberculosis promotes ossification. This may be because of the enhanced inflammation. Pro-inflammatory molecules including interleukin-1 and -17, and tumor necrosis factor-alpha boost ossification $[14,15]$.

\section{Conclusions}

Spondylitis tuberculosis due to $M$. tuberculosis infection supports enhances ossification and new bone formation by stimulating calcium metabolism in lesions.

\section{Conflict of Interest}

No potential conflict of interest relevant to this article was reported.

\section{Acknowledgments}

The Research has grant from Riset Unggulan Universitas Indonesia 2012.

\section{References}

1. Sapardan S. Total treatment of tuberculosis of the spine, a rational probelm solving approach [dissertation]. Jakarta: Perpustakaan Universitas Indonesia; 2004.

2. Gottfried ON, Dailey AT. Mesenchymal stem cell and gene therapies for spinal fusion. Neurosurgery 2008;63:380-91.

3. Leonardi E, Ciapetti G, Baglio SR, Devescovi V, Baldini N, Granchi D. Osteogenic properties of late adherent subpopulations of human bone marrow stromal cells. Histochem Cell Biol 2009;132:547-57.

4. Nather A, David V, Teng JW, Lee CW, Pereira BP. Ef- fect of autologous mesenchymal stem cells on biological healing of allografts in critical-sized tibial defects simulated in adult rabbits. Ann Acad Med Singapore 2010;39:599-606.

5. Vats A, Tolley NS, Buttery LD, Polak JM. The stem cell in orthopaedic surgery. J Bone Joint Surg Br 2004;86:159-64.

6. Bilousova G, Jun du H, King KB, et al. Osteoblasts derived from induced pluripotent stem cells form calcified structures in scaffolds both in vitro and in vivo. Stem Cells 2011;29:206-16.

7. Nair SP, Meghji S, Wilson M, Reddi K, White P, Henderson B. Bacterially induced bone destruction: mechanisms and misconceptions. Infect Immun 1996;64:2371-80.

8. Bozic KJ, Glazer PA, Zurakowski D, Simon BJ, Lipson SJ, Hayes WC. In vivo evaluation of coralline hydroxyapatite and direct current electrical stimulation in lumbar spinal fusion. Spine (Phila Pa 1976) 1999;24:2127-33.

9. Zhang G, Zhu B, Shi W, Wang M, Da Z, Zhang Y. Evaluation of mycobacterial virulence using rabbit skin liquefaction model. Virulence 2010;1:156-63.

10. Bierry G, Jehl F, Prevost G, et al. Percutaneous inoculated rabbit model of intervertebral disc space infection: magnetic resonance imaging features with pathological correlation. Joint Bone Spine 2008;75:46570.

11. Chan JK. A study of osteocyte apoptosis by region and quadrant in murine cortical bone [dissertation]. San Luis Obispo (CA): California Polytechnic State University; 2011.

12. Sanchez-Fernandez MA, Gallois A, Riedl T, Jurdic P, Hoflack B. Osteoclasts control osteoblast chemotaxis via PDGF-BB/PDGF receptor beta signaling. PLoS One 2008;3:e3537.

13. Zychowicz ME. Osteoarticular manifestations of Mycobacterium tuberculosis infection. Orthop Nurs 2010;29:400-6.

14. Thomas MV, Puleo DA. Infection, inflammation, and bone regeneration: a paradoxical relationship. J Dent Res 2011;90:1052-61.

15. Nam D, Mau E, Wang Y, et al. T-lymphocytes enable osteoblast maturation via IL-17F during the early phase of fracture repair. PLoS One 2012;7:e40044. 